\title{
Pesquisa Translacional: uma interpretação
}

\author{
Translational research: an interpretation
}

\footnotetext{
${ }^{1}$ Associação Brasileira das Indústrias de Química Fina, Biotecnologia e suas Especialidades (ABIFINA). Av. Churchill 129/1102, Centro. 20020-050 Rio de Janeiro RJ. reinaldo.guimaraes47@ gmail.com
}

\begin{abstract}
Translational Research (TR) appears to be developing into the key health research issue of the beginning of this century. Initially proposed in the United States, TR is spread rapidly throughout both the developed and the developing world. This article discusses the main topics it covers, such as its definition and scope and the reasons why it has emerged in the USA and in this century. It examines the relationship between $T R$ and the basic principles of US scientific policy established at the end of World War II. It sees the demands of a mighty pharmaceutical industry, currently facing a major crisis, linked to scientific genomic and post-genomic output impairments in terms of real innovative products and processes as being the explanation for US government intervention in biomedical research via the NIH. It realizes that it is not easy to predict the future of TR and suggests that it is not sustained by a solid conceptual and theoretical framework. It also discusses the opportunities and possibilities of TR in countries with nascent national innovative systems, such as Brazil. Lastly, it suggests that the existence of a universal health system can be an important tool to provide potential research answers tin health for the demands of innovation on the part of society.
\end{abstract}

Key words Scientific policy, Technological policy, Translational research, Translational medicine, Translational science
Resumo A Pesquisa Translacional (TR) parece estar se tornando o principal mote da pesquisa em saúde neste início de século. Nascida nos Estados Unidos da América (EUA), vem se disseminando rapidamente pelo mundo desenvolvido bem como pela periferia. $O$ artigo discute os principais tópicos relativos a ela. A sua definição e o seu escopo, as razões de ter nascido nos EUA e o porquê de ter nascido neste século. Debate as relações entre a TR e os fundamentos da política científica nos EUA, estabelecidos ao final da Segunda Grande Guerra. Interpreta a demanda de uma indústria farmacêutica poderosa e em crise, associada a dificuldades de outputs científicos em quantidade adequada para atendê-la como um móvel suficiente para explicar a intervenção do governo norte-americano na pesquisa biomédica através do NIH. Entende que é difícil prognosticar o futuro da TR, mas que não se trata de uma proposição sustentada em terreno teórico-conceitual sólido. Tematiza também a oportunidade e as possibilidades da TR em países com sistemas nacionais de inovação imaturos, como é o caso do Brasil. Finalmente, propõe que a existência de um sistema universal de saúde seja a principal ferramenta organizadora das respostas possíveis da pesquisa em saúde às demandas de inovação por parte da sociedade.

Palavras-chave Política científica, Política tecnológica, Pesquisa translacional, Medicina translacional, Ciência translacional 


\section{Justificativa}

"Pesquisa translacional", "medicina translacional" e "ciência translacional" (daqui em frente identificadas pelo acrônimo comum de TR) parecem estar se tornando o principal mote da pesquisa em saúde neste início de século. A ideia da translação ganha o mundo. Uma busca na internet por essas expressões (Google) mostra que, além dos EUA (4.400.000 resultados), aparecem com mais de um milhão a Alemanha, o Canadá, o Reino Unido, o Japão, a China, a França, a Austrália e a Índia. A Itália mostra 920.000 resultados e os demais BRICS e a Coréia do Sul entre 300.000 e 400.000. Com exceção da Suécia, que é um ator científico relevante no campo da saúde e aparece com 438.000 resultados, a distribuição quantitativa dos países acompanha, grosso modo, sua atuação científica geral quando medida por número de publicações ou citações.

Em 2009, foi lançada a revista Science Translational Medicine, agregada à famosa família de periódicos capitaneada pela semanal Science. A nova revista se propõe a cobrir a pesquisa básica, translacional e clínica. Existe ainda pelo menos uma revista prestigiosa sobre o tema, o Journal of Translational Medicine (virtual e de acesso livre) e algumas outras com índice de impacto menor. Mas a translação ganha terreno também no capítulo das especialidades e subespecialidades. A epidemiologia translacional tem espaço em publicações de grande impacto, como é o American Journal of Epidemiology $y^{1}$. Encontramos também um programa de pós-graduação em Cirurgia Translacional em universidade brasileira de primeira linha, o registro de marca de uma revista científica na mesma especialidade, o Journal of Translational Surgery, bem como registros de artigos ou programas docentes referidos à urologia, oftalmologia e ortopedia, todas translacionais. Tratase, como se vê, de uma marca bem sucedida.

Como se verá mais adiante, muito embora a TR seja uma inovação nascida nos Estados Unidos da América, seus impactos já se fazem sentir na organização política e institucional da pesquisa em saúde em muitos outros países, inclusive no Brasil. Daí a necessidade de a conhecermos e a analisarmos. Este é o objetivo deste texto.

\section{As origens}

Em sua origem, o termo TR esteve associado a pesquisas realizadas no Instituto Nacional de Câncer dos Estados Unidos (NCI) e apenas na primeira década deste século foi expandida para outros campos de pesquisa em saúde. Em 2003, os National Institutes of Health (NIH) publicaram os resultados de uma ampla consulta nacional realizada em 2002 e dirigida à comunidade científica com o objetivo de orientar sua política de longo prazo $^{2}$. Nesta, foram identificados três grandes alvos de atuação, sendo um deles chamado de "Reengenharia da Iniciativa de Pesquisa Clínica”. Neste alvo, entre outras ações, foi destacado o fomento ao "estabelecimento de ambientes acadêmicos para a pesquisa clínica e translacional"3. O passo seguinte deu-se em 2006, com a criação, no mesmo NIH, de uma linha de fomento institucional vinculada especificamente a esse alvo, os "Apoios para a Pesquisa Clínica e Translacional (CTSA)”. Finalmente, em 2012 foi criada uma nova unidade do NIH, dedicada especificamente ao apoio para criação de centros de pesquisa voltados à TR; o "Centro Nacional para o Avanço das Ciências Translacionais (NCATS)”.

\section{A definição e o escopo \\ da pesquisa translacional}

O que vem a ser TR? Em sua pré-história, em 1992 no NCI, ela buscava "promover pesquisa interdisciplinar e acelerar a troca bidirecional entre ciência básica e clínica para mover os achados de pesquisa básica do laboratório para ambientes aplicados envolvendo pacientes e populações" ". Desde então a noção de TR foi incorporando mais e mais "etapas" na cadeia de conhecimento, transbordando de aspectos inerentes à pesquisa e desenvolvimento, chegando a englobar processos produtivos e mesmo a incorporação de novos produtos e processos nas práticas de cuidado à saúde.

Ainda no início dos anos 2000, ficou claro que a proposta de TR dizia respeito a temas muito amplos. Mais especificamente, para que a TR atingisse os objetivos originalmente propostos, deveria levar em conta aspectos relativos à pesquisa científica, ao desenvolvimento tecnológico, à pesquisa clínica, ao processo produtivo industrial, ao mundo da regulação, à comercialização de produtos e, não menos importante, aos próprios sistemas de saúde. Uma primeira tentativa para sistematizar esta complexa rede de relações e interesses foi publicada em $2003^{5}$, tinha como foco a pesquisa clínica e aí foram identificados dois campos distintos de compreensão e de intervenção: o primeiro dizia respeito aos fatores que impediam a translação das descobertas científicas básicas para os estudos clínicos e a segunda aos fatores que barravam a translação destes para a prática 
médica e à tomada de decisão nos sistemas de saúde. Posteriormente, essa primeira tentativa foi ainda mais ampliada e especificada. Em 2007, pesquisadores do Center for Disease Control and Prevention (CDC), tendo como foco específico a pesquisa em genômica ${ }^{6}$ propuseram a existência de quatro fases dentro do escopo da TR, quais seriam: na fase T1 haveria a translação da pesquisa básica para uma "aplicação candidata" em saúde; na fase T2 a pesquisa avaliaria o valor da aplicação genômica para a prática de saúde levando ao desenvolvimento de "guidelines" baseados em evidências; na fase T3 a pesquisa tentaria mover esses guidelines para a prática de saúde, mediante a entrega, disseminação ou difusão; finalmente, na fase T4 a translação procuraria avaliar os desfechos reais da aplicação genômica na prática do cuidado à saúde.

Ainda mais recentemente, o "campo" da TR vem se ampliando para além das fronteiras médico-biológicas e sanitário-industriais, ousando incorporar aspectos econômicos, sociológicos, jurídicos e éticos. Um exemplo disso é um recente projeto tri-nacional (Áustria, Finlândia e Alemanha), também focado em TR no campo da genômica e pós-genômica ${ }^{7}$, cuja justificativa é apresentada como: Translational activities in biomedical research are advocated as a solution to several challenges... [including]... to integrate public health aspects as well as social, ethical and legal aspects into biomedical research.

Muito provavelmente, foi essa expansão de campos envolvidos no tema a responsável pela correspondente expansão do escopo do substantivo que é modificado pelo adjetivo "translacional". Em seus tempos iniciais, era a "pesquisa" translacional (cf. T1 e T2, acima). No momento em que a translação se expande para outros aspectos de práticas de saúde sem relação direta com a pesquisa, nasce a "medicina translacional" (cf. T3 e T4, acima). Quando temas como o comércio, a ética e o direito são admitidos no campo translacional (como exposto nos objetivos do projeto TRI-GEN), apresenta-se a necessidade de uma "ciência" translacional.

\section{O berço da pesquisa translacional. Por que nos EUA?}

Uma das principais formas de exercício da hegemonia norte-americana em termos globais dá-se no plano cultural. Escorada nos terrenos do seu poder econômico e militar a utilização da cultura como ferramenta de construção de hegemonia está contida no conceito mais amplo de soft power que pode ser definido como a utilização por um país de seus valores culturais ou políticos no âmbito da política externa ${ }^{8}$. Para citar um exemplo de sua utilização, vale lembrar que os primeiros movimentos de distensão no período da guerra fria (1945-1989) ocorreram nos terrenos científico, artístico e desportivo. Esse comentário objetiva a indagação: haveria outro lugar no mundo onde o aparecimento da TR tivesse um berço mais adequado e, principalmente, uma expansão da mesma na magnitude que estamos testemunhando? Muito provavelmente não. Daí decorre a minha hipótese de que essa expansão em escala global tem muito mais a ver com a geografia de sua origem do que com o seu eventual valor enquanto aquisição teórica e mesmo como ferramenta operacional relevante no plano mundial. Esta afirmativa será discutida ao longo do texto.

Dentre os grandes campos da investigação científica, o da pesquisa em saúde é aquele no qual os Estados Unidos mais se distanciam de quaisquer competidores. Os últimos dados consolidados disponíveis sobre os dispêndios globais com pesquisa e desenvolvimento em saúde humana são de $2005^{9}$. Naquele ano estimava-se que US\$ 160,3 bilhões haviam sido despendidos com P\&D em saúde no mundo, sendo que a fonte de 51\% foi privada, de $41 \%$ foi pública e de $8 \%$ foi da filantropia. Naquele mesmo ano, o orçamento do NIH, a principal fonte de recursos financeiros federais para a pesquisa científica nos EUA foi de US\$ 27,8 bilhões ${ }^{10}$. Vale ainda dizer que a maior parte desses recursos foi despendida com projetos no campo da pesquisa biomédica. Esses números revelam que os EUA, através do NIH, foram responsáveis por 42,2\% dos dispêndios públicos globais com pesquisa em saúde humana. No entanto, para um balanço mais preciso, torna-se necessário somar ao orçamento do NIH os dispêndios com pesquisa em saúde cujas fontes foram outras agências federais (NSF, NASA, etc.) e os estados da federação norte-americana. Um levantamento também referente a $2005^{11}$, revela que US\$11,51 bilhões foram oriundos daquelas fontes. Somados aos recursos do NIH, temos que naquele ano os EUA foram a origem de cerca de $60 \%$ de todos os recursos públicos globais destinados à pesquisa em saúde.

Analisada segundo outra óptica, a da distribuição interna dos recursos federais para pesquisa e desenvolvimento, a imensa expressão da pesquisa em saúde nos EUA fica ainda mais clara. No orçamento federal proposto para 2013, a distribuição por agências está na Tabela 1. 


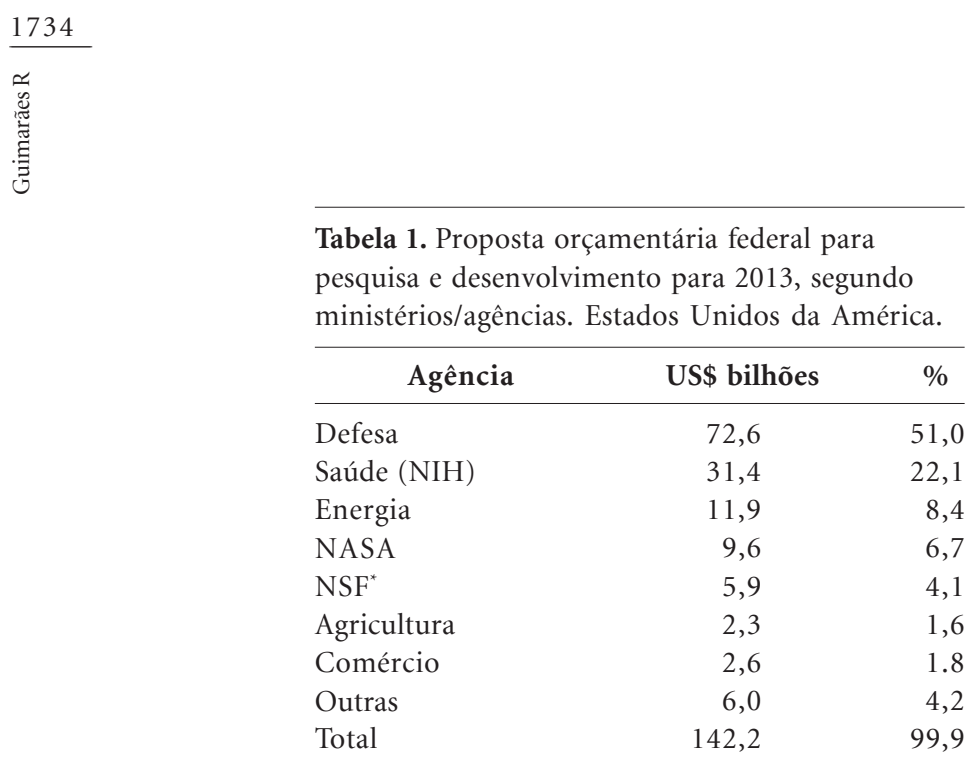

* National Science Foundation, agência de fomento à pesquisa assemelhada ao CNPq.

Fonte: Matt Hourihan ${ }^{12}$

É a força que decorre desse notável esforço de fomento à pesquisa em saúde - biomédica, epidemiológica e clínica - esforço que se projeta globalmente e que se expressa na presença maciça de trabalhos nas melhores revistas e nas centenas de milhares de cooperações científicas com pesquisadores da maioria dos países, que sugere a explicação de porque a TR nasceu nos EUA e, principalmente, porque se espalhou tão intensa e rapidamente para todo o planeta.

\section{A pesquisa translacional e os fundamentos da política científica nos EUA}

Mas, se aí nasceu e daí se disseminou, resta responder a outra pergunta: por que nesta virada de século? Qual ou quais traços de conjuntura fizeram nascer e prosperar a ideia de que a máquina norte-americana de pesquisa científica em saúde - em particular a locomotiva da máquina, a pesquisa biomédica - deveria ser orientada para algo que não fosse governado exclusivamente pelo talento e pela imaginação criativa de seus pesquisadores? E mais, por que a comunidade científica norte-americana, amadurecida nos ideais liberais da liberdade de pesquisa e principalmente na ideia, hoje algo mítica, de que a pesquisa livre e desinteressada - a pesquisa básica deve governar o avanço da técnica, por que essa comunidade e também o público em geral parecem estar se deixando levar por essa nova e explícita maneira de organizar a pesquisa?

A defesa da pesquisa básica, contra a ascensão da TR, teve um momento de embate na discussão do orçamento do NIH em 2011/2012. Aí, os principais baluartes da pesquisa biomédica nos
EUA, a saber, a Federação das Sociedades de Biologia Experimental (FASEB), a Associação Americana para o Avanço da Ciência (AAAS) e a Associação das Universidades Americanas, resistiram à alocação de recursos à TR e também a outro programa de fomento institucional do NIH, mais antigo, denominado "Pesquisa Inovadora em Pequenos Negócios” (SBIR) ${ }^{13}$. O centro da argumentação dessas entidades foi que as atividades de pesquisa translacional deveriam ser orçamentadas exclusivamente com "dinheiro novo", sem comprometer os recursos destinados à pesquisa básica, em particular a biomédica (responsável por pouco mais de $50 \%$ do orçamento do $\mathrm{NIH}$ ). $\mathrm{O}$ argumento ganha peso quando se sabe que, atualmente, a "taxa de sucesso" (proporção de propostas aprovadas em relação às apresentadas) para um projeto que solicita financiamento numa linha regular do NIH não passa de $17 \%$.

Ainda mais recentemente, em artigo da revista Scientific American ${ }^{14}$, o autor relembra e apoia a tradição da pesquisa científica nos EUA. Pela clareza e contundência com que expõe seu ponto de vista, vale a pena a transcrição de um trecho:

...In the last few years this kind of thinking [a TR] has swamped the public discourse on science. ... The NIH, the largest biomedical research agency in the world, has also embraced a new National Center for Advancing Translational Research. The director of the NIH... has not tired of pointing out the exciting advances in discovering new drugs which would be made possible by harnessing data from the human genome project.... All this makes the idea of translational research sound promising. And yet there must be a good reason why distinguished Nobel Prize winners like Chalfie, Steitz, Goldstein and Brown bristle at the mention of translational research. ... What is wrong is that translational research is being seen as a panacea that will address the flagging rate of new biomedical advances...

No nosso modo de ver, o autor expressa sua convicção baseado num pilar fundamental da construção da imagem da ciência e da pesquisa nos EUA, bem como de sua política de ciência e tecnologia, expressas num muito conhecido e reputado relatório assinado por um assessor dos presidentes Roosevelt e Truman, Vannevar Bush. Foi publicado em 1945 e se intitula Science, the Endless Frontier $^{15}$. Bush sustenta dois princípios que, em sua opinião, deveriam ser os organizadores do esforço científico norte americano nos então novos tempos de paz: (1) o principal pilar da política científica é a pesquisa básica e a ênfase na pesquisa aplicada prejudica o desenvolvimento daquela; (2) 
o progresso técnico é o ponto de chegada de um processo que se inicia na pesquisa básica.

O segundo princípio de Bush foi atropelado em meados da década de 1960, com a emergência do boom econômico japonês, assentado num modelo tecnológico onde a pesquisa científica básica não teve maior relevância. Esse então novo modelo e os outros que se apresentaram mais tarde (Coreia do Sul e China em particular) foram adequadamente estudados por grupos de cientistas sociais da tecnologia na Europa e também nos EUA, com destaque para os que construíram o conceito de Sistemas Nacionais de Inovação ${ }^{16}$. Entretanto, o primeiro postulado, que rezava a proeminência da pesquisa básica como pilar máximo do discurso sobre a política científica tem sido um princípio que, com oscilações ocasionais - a mais importante delas, segundo Smith ${ }^{17}$, ocorrida no período que vai de meados da década de 60 ao final da década seguinte permanece na ordem do dia da política científica norte-americana. Do pós-guerra imediato até hoje houve grandes ajustes práticos nesse postulado, é claro, em particular no sentido da construção de uma hoje complexa arquitetura de mediações financeiras e institucionais entre a fonte principal da pesquisa básica nos EUA - as universidades e o ponto mais frequente de chegada das aplicações científicas - as empresas - que resultaram em crescente interpenetração entre as duas esferas. Numa outra vertente, houve ajustes também no sentido de uma crescente participação de encomendas tecnológicas governamentais às universidades e institutos de pesquisa. Entretanto, em termos de prestígio e imagem pública, a pesquisa científica básica como pilar da política científica restou incólume no imaginário da comunidade científica, de boa parte da sociedade política e mesmo da população norte-americana. Sobre essa continuidade, um importante acadêmico de Harvard e conselheiro científico dos presidentes Eisenhower, Kennedy e Johnson, Harvey Brooks, argumenta que, a despeito de oscilações, a política científica permanece essencialmente inalterada desde o relatório de Bush ${ }^{18}$.

Nesse imaginário, as propostas da TR agridem de um modo contundente a visão de 1945 quanto ao papel da pesquisa básica. E não é por outra razão que a recente (2012) proposta de criação dos NCATS pelo NIH provocou reação, não apenas em segmentos da comunidade científica, como a do artigo do Scientific American e de organizações representativas da comunidade de pesquisa biomédica, já citados, como também no Congresso norte-americano ${ }^{19}$.
Entretanto, apesar das resistências na sociedade civil e política, todas as iniciativas do NIH em direção à TR (NCATS, SBIR) foram aprovadas e devidamente orçamentadas para 2013 (US\$ 575 milhões para o NCATS). A TR avança e tudo indica que terá algum sucesso em corroer de modo aberto, no campo da pesquisa em saúde humana, o primeiro postulado de Vannevar Bush sobre o primado da pesquisa básica na política científica dos EUA. A consolidação da TR como prática hegemônica no fazer científico no campo da saúde será uma alteração importante em décadas de um discurso de política científica que, mesmo que já não correspondesse à prática dessa política, ainda vinha alimentando com eficácia as projeções hegemônicas globais norte-americanas no terreno cultural-científico, bem como um dos grandes motivos de orgulho nacional. É uma evidência reveladora da liderança norteamericana no campo da pesquisa em saúde, bem como de sua utilização no terreno do soft-power a contabilidade da presença de pesquisadores norte-americanos nas listas de prêmios Nobel de Fisiologia e Medicina. Entre 1945 e 2012 foram 151 premiados e 84 eram norte-americanos $(56 \%)^{20}$. Mas, se aquele discurso é ainda funcional nos planos políticos interno e externo, por que a mudança? Para discutir uma resposta a essa questão, é necessário passar do terreno político para o econômico.

\section{Promessas frustradas?}

Há consenso hoje em dia quanto à interpretação de que a "aplicação" da pesquisa básica que alicerçou os postulados de Vannevar Bush sobre a política científica foram as bombas atômicas lançadas sobre o Japão ${ }^{21}$. As aquisições teóricas e experimentais fundamentais da física desenvolvidas no final do século XIX e na primeira metade do século XX foram expressas numa inovação, num produto, num artefato que foi imaginado por uma boa parte dos cientistas básicos envolvidos anteriormente naquelas aquisições científicas, além de ter sido construído com a participação de muitos deles no Projeto Manhattan.

Entretanto, sem maior pretensão de rigor histórico, se poderia dizer que entre o desvelamento da estrutura do DNA (1953) e o lançamento do Projeto Genoma (1990), paulatinamente, a biologia, tendo a frente as suas aquisições a nível molecular, se afirma como a "ciência líder" em substituição à física. Essa posição de "liderança" foi alcançada essencialmente nos terrenos da genética, da bioquímica e da pesquisa clínica e pode 
ser avaliada, entre outros indicadores, pelo prestígio social de disciplinas do campo biológico expresso, por exemplo, na informação quase diária dos jornais e revistas sobre novas descobertas nesses campos.

Uma das características mais importantes dessa publicidade de resultados de pesquisas é o seu "gancho" translacional. Habitualmente, há uma promessa de inovações associadas à descoberta anunciada. Mesmo que, numa avaliação equilibrada, a possibilidade da inovação (produto ou processo no mercado) esteja a muitos anos (por vezes décadas) de ser concretizada. A cura do câncer mediante anticorpos monoclonais e vacinas recombinantes, a recuperação de tecidos lesados mediante a manipulação de células-tronco e tantas outras promessas são anunciadas de tal modo que se pode conjecturar que o principal objetivo do anúncio seja o de criar um mecanismo de retroalimentação cuja materialidade mais importante talvez seja a de garantir mais recursos financeiros para a continuidade das pesquisas.

Vinculada a essas promessas e às expectativas sociais por elas criadas, crescem as dúvidas sobre se os recursos financeiros investidos nos capítulos mais dinâmicos da biologia molecular, vale dizer, a genômica, a proteômica e todas as demais "ômicas" que vieram a seguir - além da pesquisa clínica - têm atingido as etapas de translação prometidas em escala e tempo adequados. Em outros termos, crescem as dúvidas se à quantidade de dinheiro colocado à disposição "da bancada" tem correspondido em número e relevância, resultados "na beira do leito" ou "na comunidade".

Uma estimativa do volume de recursos financeiros investidos pode ser obtida a partir dos dados de desembolso recente do NIH segundo áreas de pesquisa. Aí se evidencia que, em 2011, o primeiro, o segundo e o quarto destinos dos recursos do NIH foram, respectivamente, a pesquisa clínica, a genética e a biotecnologia ${ }^{22}$. Quando medida por publicações, o crescimento da produção científica nesses campos é exponencial, conforme os Gráficos 1 e 2, que registram o número de documentos sobre a genômica e às demais "ômicas" em anos recentes, a partir dos registros existentes na base Scopus/Elsevier ${ }^{23}$.

$\mathrm{Na}$ outra ponta da translação, entretanto, essa fartura está longe de existir. De acordo com o já citado trabalho de Khoury et al. ${ }^{24}$ os autores afirmam que não mais do que $3 \%$ das publicações alcancem as etapas T2, T3 e T4.

Em outros termos, o que se passa é que, tomando como ponto de partida o projeto do Ge- noma Humano (em 1990 orçado em US\$ 15 bilhões para 15 anos), após mais de 20 anos de pesado estímulo financeiro por muitos países, com os EUA à frente, os resultados em termos de inovações decorrentes de translações desde a pes-

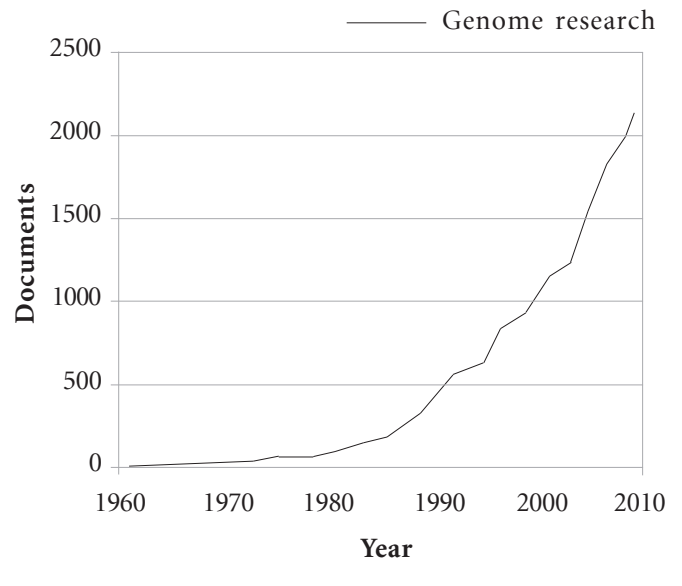

Gráfico 1. Número de documentos sobre pesquisa em genômica presentes na Base SCOPUS/Elsevier. 1960-2010.

Fonte: Jones ${ }^{23}$ (Uso do gráfico autorizado por SCOPUS/Elsevier).

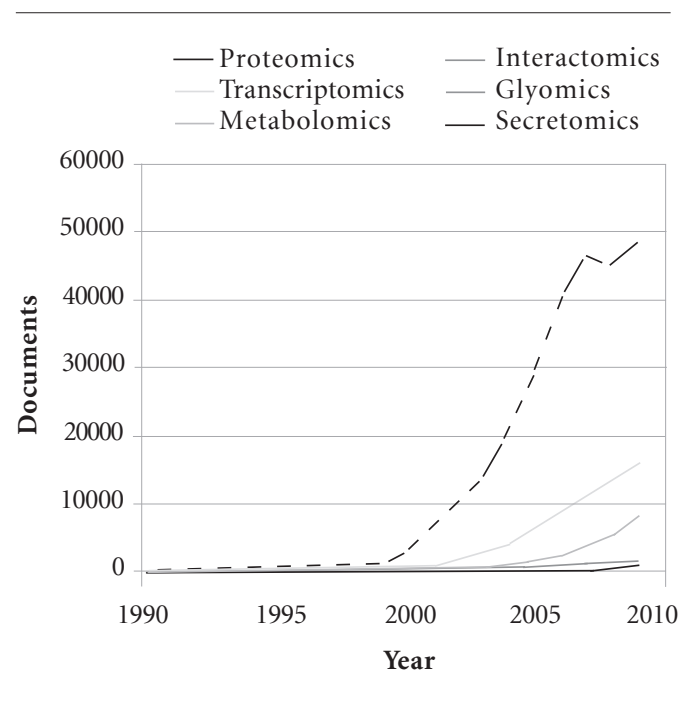

Gráfico 2. Número de documentos sobre pesquisa em áreas pós-genômicas presentes na Base SCOPUS/Elsevier. 1990-2010.

Fonte: Jones ${ }^{23}$ (Uso do gráfico autorizado por SCOPUS/Elsevier) 
quisa biomédica ainda não são entusiasmantes.

Outra evidência sobre a falta de entusiasmo com os resultados das translações diz respeito ao financiamento de empresas do tipo start-up envolvidas com projetos de TR. Além do NIH e de outras agências federais norte-americanas, esse financiamento é realizado por empresas de venture capital que captam recursos de investidores dispostos a se associar a projetos com promessa de sucesso, por tempo determinado e com participação nos lucros caso o sucesso se confirme. Nos últimos anos, a atratividade de projetos de TR em start-ups biotecnológicas não tem apresentado crescimento sustentado. A partir de 2009, o número de operações e o volume financeiro oscilam, conforme a Tabela 2. Os dados foram retirados de Art Wuster ${ }^{25}$.

É verdade que a escassez relativa de atratividade pode ser decorrente, não do desencanto dos investidores com a TR, mas da crise econômica que atingiu os EUA e a Europa a partir de 2008. Será, portanto, necessário aguardar a recuperação da economia norte-americana para confirmar ou não a tendência mostrada pelos números da figura.

O descompasso entre as aquisições científicas da biologia molecular e as inovações "na beira do leito" e "na comunidade" poderia ser decorrente de um processo natural de desenvolvimento e maturação de ideias científicas ao ponto das mesmas estarem aptas a fornecer respostas a demandas colocadas pela sociedade. É lícito conjecturar que aquele conhecimento novo talvez ainda necessite de tempo para fazê-lo.

Para explorar esse aspecto da questão, voltemos à história do grande momento da "translação" entre as aquisições teóricas e experimentais

Tabela 2. Número e Valor dos investimentos de Venture Capital em empresas biotecnológicas vinculadas à genômica. 2006-2012.

\begin{tabular}{cccc}
\hline Anos & $\begin{array}{c}\text { Número de } \\
\text { operações } \\
\text { (A) }\end{array}$ & $\begin{array}{c}\text { Valor médio } \\
\text { das operações } \\
\text { [US\$ milhões] (B) }\end{array}$ & (AxB) \\
\hline 2006 & 13 & 13,2 & 172 \\
2007 & 8 & 17,8 & 143 \\
2008 & 11 & 14,3 & 157 \\
2009 & 18 & 19,9 & 357 \\
2010 & 19 & 20,1 & 381 \\
2011 & 22 & 15,1 & 332 \\
2012 & 16 & 24,5 & 392 \\
\hline
\end{tabular}

Fonte: Modificado de Wuster ${ }^{25}$. da física do início do século XX e a sua mais visível inovação tecnológica, "colocada no mercado" em 1945. Em 1951, Robert Oppenheimer, então diretor do Laboratório Científico de Los Alamos afirmou:

"as coisas que aprendemos [durante a guerra] não são muito importantes. As coisas verdadeiramente novas foram aprendidas em 1890, 1905 e 1920, em todos os anos que conduziram à guerra, e nós pegamos essa árvore carregada de frutos maduros e a sacudimos e delas caíram o radar e as bombas atômicas... O espírito era o de uma exploração frenética e um pouco inescrupulosa do conhecido; não o de uma tentativa sóbria e modesta de penetrar o desconhecido" ${ }^{21}$.

Na nossa leitura, essa citação de um dos líderes do desenvolvimento da bomba atômica revela duas coisas importantes: em primeiro lugar, ele fala do necessário tempo de maturação de ideias científicas (os frutos devem estar maduros) para que a ciência possa responder às demandas da sociedade. Mas Oppenheimer fala também da pressão das demandas sociais para alavancar a "sacudida" na árvore (a exploração frenética e um pouco inescrupulosa do conhecido). Em outros termos, Oppenheimer sugere que a pressão da demanda, neste caso uma pressão política e militar, foi importante para acelerar a "translação".

Seria possível encontrar uma pressão de demanda correspondente capaz de explicar toda a mobilização político-institucional e os estímulos financeiro-organizacionais associados à TR na conjuntura atual? Algo que, como apontou Oppenheimer na outra conjuntura, pudesse sacudir a árvore carregada de frutos maduros da qual caíssem as inovações no campo da saúde?

\section{A crise da Indústria farmacêutica}

É viável supor que essa pressão tenha vindo de um dos mais poderosos setores industriais norte-americanos. Os Estados Unidos são líderes mundiais na descoberta, desenvolvimento, patenteamento, registro, produção e vendas de medicamentos. Com a crescente presença de tecnologias biotecnológicas, a indústria farmacêutica cada vez mais se autodenomina "biofarmacêutica”. Este mercado, em 2011 (US\$ 320 bilhões em vendas), respondeu por $37,4 \%$ do mercado coberto pelas 20 maiores empresas globais (US\$ 855 bilhões - cerca de $80 \%$ do mercado farmacêutico mundial). No mesmo ano, dentre as dez maiores empresas biofarmacêuticas no mundo, quatro (Pfizer, Merck, Johnson \& Johnson e Ab- 
bott) eram norte-americanas e responderam por cerca de 20\% do mercado global ${ }^{26}$. Em 2008 o setor respondia por 655 mil empregos diretos e 905 mil indiretos, contribuindo com US\$ 114 bilhões para o PIB dos Estados Unidos. Uma indústria com essa pujança não tem alternativa se não a de exercer o seu poder. Nota recente afirma que a indústria biofarmacêutica gastou, desde 1998, US $\$ 3,2$ bilhões com lobbies e US $\$ 183 \mathrm{mi}-$ lhões com doações de campanhas eleitorais ${ }^{27}$.

Mas a despeito de seu poder e de sua histórica lucratividade, a indústria biofarmacêutica global, inclusive a norte-americana, vive uma crise importante desde a última década do século passado, cujos principais determinantes são o aumento exponencial de custos para o desenvolvimento de novas moléculas, em particular em suas fases mais tardias de pesquisa clínica e a queda da proteção patentária de medicamentos de grande retorno financeiro. O principal indicador da crise é a diminuição do número de registros de moléculas realmente inovadoras nos principais mercados, em particular os registros feitos no Federal Drug Administration (FDA) ${ }^{28}$. Essa crise gerou uma intensa disputa entre firmas pela conquista de pipelines promissores, em particular os pertencentes a empresas de biotecnologia, sendo este campo de conhecimento considerado o caminho alternativo à escassez de moléculas novas (desenvolvidas historicamente pela rota de síntese química). A disputa se expressou por uma grande onda de fusões e aquisições, algumas destas de caráter hostil. Consulta na internet revela que, entre 2010 e 2012, no mínimo 14 empresas farmacêuticas de base biotecnológica mudaram de mãos ou se associaram a empresas biofarmacêuticas maiores. A maior transação nessa onda foi a aquisição hostil da empresa norte-americana Genzyme pela francesa Sanofi-Aventis, no valor de $€ 14,7$ bilhões.

A propósito da crise nos registros de moléculas inovadoras, vale registrar que O FDA anunciou que em 2012 foram registradas 35 novas moléculas inovadoras, número idêntico ao de 2011 e que recupera o número observado em $2004^{29}$. Pode ser o início de uma recuperação, bem como uma oscilação eventual. Há que aguardar a continuação da série.

Entretanto, as compras e as fusões não foram a única resposta do setor à crise. Além delas, a reação tem se orientado em mais quatro direções. A primeira são mudanças no modelo geral de negócios, cuja essência reside no refreamento da verticalização nos processos de desenvolvimento e produção, com crescente terceirização.
Aqui, o objetivo principal é o compartilhamento do risco. A segunda é uma mudança de atitude em relação a medicamentos genéricos, que deixaram de ser "criminalizados" e vêm sendo crescentemente incluídos nos porta-fólios das grandes empresas. A terceira tem sido o tensionamento das políticas de proteção à propriedade intelectual em vários países, com a proposição de regras cada vez mais rígidas de proteção da propriedade intelectual mediante patentes. Essas medidas são conhecidas genericamente nos fóruns internacionais como medidas Trips-Plus e várias de suas propostas restritivas têm sido incluídas nos acordos bilaterais e multilaterais de livre comércio celebrados entre os Estados Unidos e outros países. Mencione-se, por exemplo, a renúncia à aplicação de algumas flexibilidades dos acordos Trips, como a utilização de licenciamentos compulsórios. Finalmente, a quarta direção, na verdade a que chegou primeiro, é a que se poderia chamar de uma radicalização nas estratégias comerciais das grandes farmacêuticas, cujas práticas chegaram a atingir as fronteiras da ética e mesmo da legalidade, o que atestam os recentes acordos celebrados entre farmacêuticas de grande prestígio e a justiça norte-americana. Dentre estes, surpreende o que estabeleceu, em agosto de 2012, multa de US\$ 3 bilhões pelo exercício de práticas comerciais ilegais realizadas pela empresa britânica Glaxo Smith Kline durante a primeira década deste século ${ }^{30}$.

Em resumo, a situação atual da indústria farmacêutica mundial é a perda de proteção patentária de produtos geradores de grandes receitas, num ambiente de diminuição de lançamentos de novos produtos que os substituam. E como pode ser depreendido do que descrevemos acima, as medidas tomadas pelas empresas ficaram, predominantemente, a cargo dos seus departamentos, financeiro, comercial, de marketing e jurídico. Sendo, no entanto, um setor industrial que se autodenomina "de pesquisa" (rótulo correto, haja vista investimentos em P\&D das casas-matrizes em torno a $15 \%$ na receita de vendas), tornou-se essencial ouvir algo dos departamentos de P\&D. A resposta deste é a necessidade de exploração cada vez maior da rota biotecnológica, na qual o conhecimento oriundo das "ômicas" insumo fundamental da TR - é essencial.

Torno então à pergunta que foi feita mais acima: seria possível encontrar uma pressão de demanda correspondente capaz de explicar toda a mobilização político-institucional e os estímulos financeiro-organizacionais associados à TR na conjuntura atual? Algo que, como apontou Oppe- 
nheimer na outra situação, pudesse colaborar para sacudir a árvore carregada de frutos maduros e, da qual caíssem as inovações no campo da saúde?

A demanda de uma indústria farmacêutica poderosa e em crise, associada a dificuldades de outputs científicos em quantidade adequada para atendê-la pode muito bem estar exigindo a intervenção do governo norte-americano através do NIH. O objetivo essencial é o de fomentar algum tipo de esforço adicional da comunidade científica para suprir uma demanda estratégica para o país. Não se trata, a rigor, de uma nova "pesquisa", nem "medicina", nem muito menos "ciência", translacionais. Estes são nomes para marcas de fantasia. Trata-se apenas de estímulos para uma "sacudida" na árvore, para que seus frutos amadureçam e possam então cair. Resta saber se, como aconteceu em 1945, já há frutos maduros na árvore, ou se será necessário esperar mais um pouco.

Mas não se trata de menosprezar a movida. $\mathrm{O}$ movimento da TR pode significar uma adequação importante na política científica norte-americana no campo da pesquisa em saúde humana, na medida em que se consiga superar, no âmbito do discurso, aquilo que já tem uma expressão matizada na sua prática política há muito tempo: refiro-me ao princípio número 1 de Vannevar Bush, a saber: "o principal pilar da política científica é a pesquisa básica e a ênfase na pesquisa aplicada prejudica o desenvolvimento daquela”. Caso se logre este feito, não terá sido pouca coisa.

\section{Conclusão}

Qual o futuro da TR? Difícil prognosticar, mas alguns aspectos podem ser discutidos. Em primeiro lugar, tudo sugere que, a despeito de seu sucesso, não se trata de uma proposição sustentada em terreno teórico-conceitual sólido. Uma recente discussão conceitual sobre o tema ${ }^{31}$ aponta três dimensões pouco claras nas proposições sobre a TR e que as fragilizam.

A primeira delas é a extensão da "brecha" que a TR se propõe a superar. Por um lado, se considera aquela entre T1 e T2, conforme trabalho aqui citado anteriormente ${ }^{32}$. Por outro, uma bem mais ampla a superar, entre $\mathrm{T} 1$ e T4, seria o objetivo da TR. Em nosso entendimento, essa maior ou menor extensão da brecha a ser superada decorreu da contínua expansão da definição dos limites do escopo da TR, conforme discutido por nós em seção anterior deste texto.

Em segundo lugar, há uma fragilidade nas explanações quanto aos modelos explicativos da translação. Por um lado, há uma visão linear e unidirecional (da bancada para a beira do leito) que é utilizada pela maioria da bibliografia; outro modelo seria uma translação bidirecional e ainda linear (da bancada para a beira do leito e, por vezes, daí novamente para a bancada); finalmente, uma visão mais complexa, na qual o processo de translação seria um processo dinâmico e de sentido variado. Em nosso modo de ver, estes três modelos de translação nada têm de novo e correspondem, em terreno mais restrito, à discussão dos modelos gerais de explicação do progresso técnico entre o final da Segunda Guerra Mundial e os dias de hoje, a saber: o modelo linear sustentado na perspectiva science push, o modelo linear market pull e o modelo complexo, combinando estímulos de oferta e demanda e tendo a ciência básica como fonte de oportunidade estratégica ${ }^{33}$.

Em terceiro lugar, Laan e Boenink ${ }^{31}$ discutem as ambiguidades sobre a origem da brecha translacional, apontando duas tendências: a primeira que a considera fora dos marcos da ciência como, por exemplo, as dificuldades financeiras, institucionais e de canais de comunicação entre bancada e beira do leito, algo como problemas operacionais que dificultariam uma prática científica mais inclinada a superar brechas para a aplicação de descobertas científicas; a outra situa a origem da brecha ao interior mesmo do fazer científico como, por exemplo, a forma de pesquisar e a percepção que os cientistas têm de seu próprio papel profissional e social. Frisamos nós que as propostas políticas postas em prática pelo governo norte-americano através do NIH tendem a valorizar a primeira das duas visões. Os dois programas de fomento institucional que foram propostos pela agência, os Clinical and Translational Science Awards (CTSA) e os National Centers for the Advancement of Translational Science (NCATS), buscam superar supostas dificuldades operacionais que estariam tolhendo os caminhos da translação.

A despeito dessas dificuldades conceituais, vale reafirmar a importância de um alinhamento entre o discurso e a prática na política científica nos EUA. Como já observamos mais acima, a maior contribuição da TR para a cultura científica norte-americana talvez seja a produção deste alinhamento no campo da pesquisa em saúde e, em particular, na biomedicina. Entretanto, nos parece válido perguntar o porquê da construção de uma nova marca, com evidentes debilidades teóricas, quando os mesmos EUA já produziram outra construção sobre as relações entre a ciên- 
cia e a inovação tecnológica com maior abrangência (não apenas relacionada à pesquisa em saúde humana) e, mais relevante ainda, lastreada em sólida evidência teórica e histórica? Referimo-nos ao tema e às propostas discutidas por Donald Stokes em seu muito conhecido livro "O Quadrante de Pasteur", de $1997^{21}$.

Entre as inúmeras contribuições do livro de Stokes, uma das mais importantes talvez seja a análise do processo de desconstrução política do paradigma orientador das relações entre ciência e inovação nos EUA desde 1945, processo até então ainda não encerrado (o livro de Stokes é de 1997). Para o ponto em que se encontrava o debate no final do século passado, Stokes sumariza cinco pontos que deveriam orientar a sua continuidade. São eles:

1. "A visão paradigmática da ciência e da tecnologia que emergiu da Segunda Guerra Mundial forneceu uma descrição notoriamente incompleta do relacionamento real entre a pesquisa básica e a inovação tecnológica".

2. "A incompletude do paradigma do pósguerra está prejudicando o diálogo entre a comunidade cientifica e a comunidade política e atrapalhando a busca por um novo pacto entre ciência e governo".

3. "Uma visão mais realista do relacionamento entre a ciência e a tecnologia deve reservar espaço para o papel criticamente importante da pesquisa básica inspirada pelo uso, de fazer a ligação entre as trajetórias semiautônomas do entendimento científico e do conhecimento tecnológico". Vale lembrar que Stokes localiza a 'pesquisa básica inspirada pelo uso' em seu 'Quadrante de Pasteur', com o nome de pesquisa estratégica.

4. "Um entendimento mais claro, por parte das comunidades científica e política, do que a pesquisa básica inspirada pelo uso pode ajudar a renovar o pacto entre a ciência e o governo, um pacto que deve também conferir apoio à pesquisa básica pura".

5. "Só se poderão construir agendas de pesquisa básica inspirada pelo uso por meio da conjugação de avaliações bem fundamentadas das promessas de pesquisa e das necessidades da sociedade".

No nosso modo de ver, aí estaria uma boa agenda para que se pudesse encaminhar uma discussão sobre o futuro da TR. Uma agenda politicamente comprometida e conceitualmente fundamentada.

Um segundo aspecto a ser discutido é a eficácia e a sustentabilidade da TR fora das fronteiras norte-americanas. Se a nossa interpretação da sinergia conjuntural de interesses entre indústria (demanda), comunidade científica da saúde (oferta) e governo (NIH) como motor da construção do modelo da TR for confirmada, é lícito supor que esse modelo será mais consistente e sustentável nos países com sistemas nacionais de inovação maduros ou, pelo menos, em situação de catching-up, conforme o enquadramento proposto em algumas linhas de pesquisa existentes entre nós ${ }^{34-36}$. Países com sistemas de inovação imaturos, como é o caso do Brasil, mesmo que com um parque científico importante no campo da saúde, tenderão a não reproduzir com eficiência o modelo do NIH.

\section{$\mathrm{O}$ caso brasileiro}

Se for verdadeira a interpretação abraçada nesse texto, de que a aparição e o desenvolvimento da TR nos EUA decorrem de uma conjuntura na qual a demanda estabelecida por uma indústria cujo componente tecnológico possui forte base científica, politicamente poderosa e em crise não tem sido atendida a tempo e a hora pelos resultados de pesquisas que se esperaria alimentá-la, cabe indagar sobre a inserção do Brasil nessa equação.

Como já foi observado mais acima, o discurso - e até certo ponto também a prática - da TR se dissemina desde a potência líder mundial para os outros países centrais que, como ela, são também possuidores de sistemas nacionais de inovação maduros no setor de saúde. É possível imaginar que países com sistemas em situação de $c a$ tching up sejam também crescentemente envolvidos nesse ambiente. Mesmo países com sistemas nacionais de inovação imaturos, mas com componentes setoriais diferenciados, podem estar interessados no modelo TR. Por exemplo, no exercício grosseiro de busca por documentos que tratam do tema da TR mencionado na abertura deste texto, verificamos que a Índia, que se apresenta na web num padrão similar aos países centrais e que ainda não tem um sistema nacional de inovação maduro ${ }^{37}$, por certo já amadureceu seu componente setorial de saúde mediante o desenvolvimento de uma poderosa indústria farmacêutica, hoje em dia um player mundial.

Não é o caso brasileiro. Muito embora em franca evolução no último decênio (para a indústria farmacêutica $)^{38}$, o nosso sistema nacional de inovação, incluído aí seu componente setorial de saúde ainda não foi capaz de desenvolver as instituições e os mecanismos suficientes para que se 
possa considerar que entramos numa fase de $c a-$ tching-u $p^{37}$. Na vertente mais desenvolvida desse sistema, que está no lado da oferta, o país vem galgando posições no cenário internacional conforme revelam os levantamentos em bases de dados que indexam trabalhos publicados, bem como na massa crítica envolvida. E neste contexto, o setor de saúde humana é um dos destaques ${ }^{39}$. Na comparação interna, o setor de saúde humana é aquele com maior capacidade instalada, seja em número de grupos de pesquisa ativos ${ }^{40}$, seja em número de programas de pós-graduação recomendados, segundo a CAPES/MEC.

A vertente da demanda, entretanto, revela um complexo industrial da saúde ainda em desenvolvimento, seja quando relacionado com a complexidade e o tamanho da economia brasileira, seja com a dimensão do mercado interno, seja com sua projeção no mercado global. No segmento de equipamentos de saúde, observam-se concentração e internacionalização crescentes, em particular nos nichos mais intensos em tecnologia (eletroeletrônico, óptico e de mecânica de precisão). No segmento de vacinas a presença quase exclusiva do setor público no desenvolvimento e produção é, por um lado, solução (regulação de mercado e melhor aderência da produção às prioridades de saúde pública), mas é também um problema (maior dificuldade no desenvolvimento e introdução de vacinas modernas). E no segmento farmoquímico/farmacêutico, o quadro enseja otimismo, mas com a consciência de que os desafios são ainda gigantescos. Após sua quase completa destruição durante o período de abertura comercial dos anos 90 (principalmente no componente farmoquímico), a partir da introdução da Lei dos genéricos (2000) vem se observando um crescimento vigoroso e sustentado. Indústrias de capital nacional encontram-se hoje entre as maiores do mercado brasileiro e ensaiam seus primeiros passos consistentes na busca do desenvolvimento de produtos inovadores. Entretanto, se a aposta no nicho dos genéricos vem garantindo até hoje certa imunidade da indústria brasileira face à crise da Farma mundial, o crescimento das atividades mais sofisticadas de inovação farão com que essa imunidade diminua muito de intensidade. Em particular no universo das rotas produtivas biológicas.

Tal qual no segmento dos equipamentos, no ambiente farmoquímico/farmacêutico há também um processo de internacionalização em curso. No nosso tema, que é a relação entre a criação científica e a solução de problemas de saúde mediante produtos e processos inovadores, a in- ternacionalização é uma ameaça importante, haja vista que as empresas multinacionais têm dificuldade de realizar etapas importantes de pesquisa e desenvolvimento em países periféricos. A quase totalidade das despesas realizadas no Brasil declaradas por empresas farmacêuticas transnacionais dizem respeito a ensaios clínicos em suas fases III e IV, nos quais quase não existe participação de grupos de pesquisa de bancada. Além disso, nesses ensaios, os graus de liberdade dos pesquisadores clínicos brasileiros costumam ser muito limitados pela adesão estrita a protocolos elaborados também no exterior.

Não é nova a constatação de que, entre outras, as dificuldades enfrentadas pelas políticas de ciência, tecnologia e inovação no Brasil residem no fato de que o nosso sistema científicotecnológico se organiza essencialmente segundo padrões de oferta de conhecimento. Menos, talvez, pelo grande e sustentado apoio aos grupos de pesquisa científica ao longo do tempo e mais pelo padrão de industrialização brasileiro, desde os anos 50 do século passado ${ }^{41}$. Visto por outro ângulo, as dificuldades e a intermitência nas relações entre a pesquisa científica, a tecnologia e as inovações ocorreriam menos por uma falta de preocupação dos pesquisadores em orientar suas atividades para responder às demandas do setor produtivo, e mais pela ausência dessa demanda em direção às atividades de pesquisa que embutam promessas de serem desenvolvidas.

É no contexto das relações entre oferta e demanda de conhecimento no campo da saúde humana que se situa a proposta da TR. Seu objetivo, como vimos, é alterar a forma de relacionamento entre os pesquisadores e a indústria a partir de um reforço na oferta, que hoje em dia estaria aquém das exigências das demandas das empresas farmacêuticas. Uma alteração, portanto, nas tradicionais e intensas relações universidadeempresa nos países centrais. Esta, decididamente, não é a situação brasileira. Para nós, o foco principal do problema é estimular a demanda das empresas (e também do sistema de saúde). Apenas secundariamente, buscar reorientar ou mesmo estimular a oferta de conhecimento.

Estudo recente revela que as relações entre grupos de pesquisa e empresas no Brasil vêm crescendo $^{42}$. Entretanto, sugere também que elas são mais fortes nas situações nas quais estão envolvidas tecnologias de média e baixa intensidade. Além disso, a indústria da saúde não é especialmente mencionada como uma das "campeãs" no item da interação com as universidades. Enfatizamos este último aspecto na medida em que 
a TR envolve especialmente atividades genômicas e pós-genômicas no campo da biologia molecular, isto é, atividades de alta tecnologia.

Entretanto, a situação brasileira introduz outra vertente de análise, que é a existência de um sistema de saúde público e universal potencialmente demandante e um mercado interno importante e crescente como consequência de políticas de inclusão social. Daí que uma política industrial setorial fortemente fomentada pelo mercado público poderá vir a ser um caminho para o desenvolvimento de uma indústria da saúde hoje ainda carente de densidade tecnológica autóctone, mas que poderá se tornar, no médio prazo, demandante regular de conhecimento ao parque científico de saúde. No entanto, esse caminho ganhará maior viabilidade no contexto da construção de uma política setorial de ciência, tecnologia e inovação na qual o gestor do sistema público de saúde tenha grande presença e, por que não dizer, posição de liderança. Em outras palavras, uma política na qual a demanda da sociedade por mais e melhores serviços e produtos de saúde tenha um papel central.

Desde o ano 2000, com a criação do Departamento de Ciência e Tecnologia do Ministério da Saúde e, principalmente a partir de 2003 com a inauguração da sua Secretaria de Ciência, Tecnologia e Insumos Estratégicos, o ministério está minimamente apetrechado para o cumprimento dessa missão. Resta perseverar na construção dessa política que, a nosso ver, nos últimos dez anos talvez tenha avançado mais no lado da de- manda, através do fortalecimento do mercado público como demandante do Complexo Industrial da Saúde brasileiro ${ }^{43}$. Estratégia correta, uma vez que a mobilização da nossa capacidade instalada em pesquisa científica dar-se-á por pressões de demanda desse complexo.

Entretanto, no nosso entender, para que uma política dessa natureza seja consequente, o gestor público deve liderar também a política no que se refere à organização da oferta de conhecimento, mediante o fomento aos grupos que realizam pesquisa científica no campo da saúde, pari passu ao fortalecimento da capacidade inovadora das empresas do complexo da saúde. Entendemos que, se ao fortalecimento que já começa a ser observado pelo lado da demanda, não corresponder um correspondente - pelo Ministério da Saúde em cooperação com o Ministério da Ciência, Tecnologia e Inovação - da oferta, poderemos chegar a desconfortável situação de uma árvore sem "frutos a serem sacudidos", conforme a metáfora de Robert Oppenheimer.

Para tanto, será necessário um olhar especial para todo o amplo leque da investigação científica em saúde - biomédica, clínica, tecnológica e epidemiológica - de modo a priorizar as linhas mais promissoras, muitas delas na vertente denominada por Stokes como 'pesquisa básica inspirada pelo uso'. Mais do que programas de pesquisa, medicina ou ciência translacionais, este pode ser um caminho para contribuir com o amadurecimento de nosso sistema nacional setorial de inovação. 


\section{Referências}

1. Khoury MJ, Gwinn M, Ioannides JP. The Emergency of Translational Epidemiology: from scientific discovery to population health impact. Am J Epidemiol 2010; 172(5):517-524.

2. Zerhouni EA. Translational and clinical sciencetime for a new vision. $N$ Engl J Med 2005; 353(15): 1621-1623.

3. NIH Roadmap for Medical Research. National Institutes of Health. Fact Sheet. August, 2006. [documento da internet]. [acessado 2013 jan 16]. Disponível em: http://opasi.nih.gov/documents/NIH Roadmap_FactSheet_Aug06.pdf.

4. Advancing Translational Cancer Research: A Vision of the Cancer Center and SPORE Programs of the Future Report of the P30/P50 Ad Hoc Working Group February 2003. [documento da internet]. [acessado 2013 jan 12]. Disponível em: http:// deainfo.nci.nih.gov/advisory/ncab/workgroup/p30p50/P30-P50final12feb03.pdf

5. Sung NS, Crowley Júnior WF, Genel M, Salber P, Sandy L, Sherwood LM, Johnson SB, Catanese V, Tilson H, Getz K, Larson EL, Scheinberg D, Reece EA, Slavkin H, Dobs A, Grebb J, Martinez RA, Korn A, Rimoin D. Central Challenges Facing the National Clinical Research Enterprise. JAMA 2003; 289(10):1278-1287.

6. Khoury MJ, Gwinn M, Yoon PW, Dowling N, Moore $\mathrm{CA}$, Bradley L. The continuum of translation research in genomic medicine: how can we accelerate the appropriate integration of human genome discoveries into healthcare and disease prevention? Genet Med 2007; 9(10):665-674.

7. Translational research in genomic medicine: Institutional and social aspects (Tri-Gen). [Documento da internet]. [acessado $2013 \mathrm{fev}$ 02]. Disponível em: http://www.isi.fraunhofer.de/isi-de/t/projekte/sbtri-gen.php.

8. Nye Júnior J. Public Diplomacy and Soft Power. The Annals of the American Academy of Political and Social Science [documento da internet]. 2008 [acessado 2013 jan 31]; 616: 94. Disponível em: ann.sage pub.com

9. Burke MA, Matlin SA, editors. Global Forum for Health Research, Monitoring Financial Flows for Health Research 2008 In: Global Forum for Health Research; nov 2008; Bamako. p. XV.

10. American Association for the Advancement of Science. R\&D Budget and Policy Program. Guide to R\&D Funding Data - Archives Fy 2005 R\&D. [acessado 2013 jan 18]. Disponível em: www.aaas.org/ spp/rd/fy05.htm.

11. Research America: An Alliance for Discoveries in Health. Investment in U.S. Health Research. [documento da internet]. 2005 [acessado 2013 jan 18]. Disponível em: www.researchamerica.org/app/webroot/uploads/healthdollar2005.pdf

12. Matt Hourihan. November 7, 2012. The Federal R\&D Budget: Process and Perspectives - AAAS R\&D Budget and Policy Program. [documento da internet]. [acessado 2013 maio 4]. Disponível em: http:/ /www.aaas.org/spp/rd
13. Usdin S. Lost in translation: U.S. budget fight over basic, translational research spending by NIH. Biocentury 2011; [acessado 2013 jan 20]. Disponível em: http://www.biocentury.com/promotions/budgetfight/us-budget-fight-over-basic-translationalresearch-spending-by-nih-a1.htm.

14. Jogalekar A. The perils of translational research. Scientific American 2012; Nov 26. [acessado 2013 jan 20]. Disponível em: http://blogs.scientific american.com/the-curious-wavefunction/2012/11/ 26/the-perils-of-translational-research/.

15. Bush V. Science, the Endless Frontier. [acessado 2013 jan 2]. Disponível em: http://www.nsf.gov/od/ lpa/nsf50/vbush1945.htm.

16. Villela TN, Magacho LAM. Abordagem histórica do Sistema Nacional de Inovação e o papel das Incubadoras de Empresas na interação entre agentes deste sistema. [acessado 2013 jan 15]. Disponível em: http:// www.redetec.org.br/publique/media/PUC-Rio-T2_1.pdf.

17. Smith BLR. American science policy since World War II. In: Smith BLR, editor. Policy Dissarray, 19661980. Washington: The Brookings Institution; 1990. p.73-107.

18. Smith BLR. American science policy since World War II. In: Smith BLR.The Reagan era:a new consensus?. Washington, D.C.: The Brookings Institution; 1990. p.109.

19. Wadman M. NIH director grilled over translational research centre. Nature News Blog. [acessado 2013 mar 20]. Disponível em: http://blogs.nature.com/ news/2012/03/nih-director-grilled-over-translational-research-center.html.

20. Wikipedia. List of Nobel laureates in Physiology or Medicine; 2013. [acessado 2013 fev 12]. Disponível em: http://en.wikipedia.org/wiki/List_of_Nobel_ laureates_in_Physiology_or_Medicine.

21. Stokes D.E. - O quadrante de Pasteur: a ciência básica e a inovação tecnológica. Tradução de José Emílio Maiorino. Campinas, SP: Editora da UNICAMP; 2005. p. 16-20.

22. National Institutes of Health. Estimates of Funding for Various Research, Condition, and Disease Categories (RCDC); 2012. (Table Published Febr 13). [acessado 2013 jan 30]. Disponível em: report.nih.gov/ categorical_spending.aspx.

23. Jones T. Research Trends. September 2010. "Omics": genomics' offspring shed light on biodiversity. [acessado 2013 jan 20]. Disponível em: www. researchtrends.com/issue 19 -september-2010/ $\%$ E2\% $\%$ \% 9 Comics $\%$ E2\%80\%9D-genomics $\%$ E2 $\% 80 \% 99$-offspring-shed-light-on-biodiversity/.

24. Khoury MJ, Gwinn M, Yoon PW, Dowling N, Moore CA, Bradley L. The continuum of translation research in genomic medicine: how can we accelerate the appropriate integration of human genome discoveries into healthcare and disease prevention? Genet Med 2007; 9(10):665-674. 
25. Wuster A. Seqonomics: The Economics of Personalised Medicine. How bad a year has 2012 actually been for genomic investments? [acessado 2013 jan 24]. Disponível em: http://seqonomics.blogspot. com.br/2012/08/could-2012-be-best-year-everfor.html.

26. IMS Health. Top-Line Market Data. Top 20 Global Corporations, 2011, Total Audited Markets. [acessado 2013 fev 14]. Disponível em: http://www. imshealth.com/portal/site/ims/menuitem.5ad1c 081663 fdf9b41d84b903208c22a/?vgnextoid=fbc 65890d33ee210VgnVCM10000071812ca2RCRD\&vgnext $\mathrm{fmt}=$ default.

27. Huff Post Politics. Auction 2012: How Drug Companies Game Washington. [documento da inter net]. [acessado 2013 mar 19]. Disponível em: www.huffingtonpost.com/2012/02/01auction-2012drug-companies-lobby_n_1245543.html.

28. Kaitin KI. Deconstructing the Drug Development Process: The New Face of Innovation. Clinical Pharmacology o Therapeutics 2010; 87(3):356-361.

29. Reuters US Edition - FDA new drug approvals hit 16year high in 2012. [documento da internet]. [acessado 2013 fev 18]. Disponível em: http://www. reuters.com/article/2012/12/31/us-pharmaceuticalsfda-approvals-idUSBRE8BU0EK20121231.

30. USA Today. Money. Drug giant Glaxo pleads guilty, fined \$3B for drug marketing. [documento da internet]. [acessado 2013 mar 19].Disponível em: http://usatoday30.usatoday.com/money/industries/ health/drugs/story/2012-07-02/glaxosmithklinepleads-guilty-3B-fine-illicit-promotion-prescription-drugs/55979616/1

31. Laan ALVD, Boenink M. Beyond Bench and Bedside: Disentangling the Concept of Translational Research. Health Care Anal 2012; Dec. [acessado 2013 jan 25]. Disponível em: http://download. springer.com/static/pdf/423/art\%253A10.1007\%252 Fs10728-012-0236-x.pdf?auth66=1361368928_915a2 add5d2d0baaf8bb086e0d6b1214\&ext=.pdf

32. Khoury MJ, Gwinn M, Yoon PW, Dowling N, Moore CA, Bradley L. The continuum of translation research in genomic medicine: how can we accelerate the appropriate integration of human genome discoveries into healthcare and disease prevention? Genet Med 2007; 9(10):665-674.

33. Ruivo B. 'Phases' or 'paradigms' of Science policy? Science and Public Policy 1994; 21(3):157-164.

34. Albuquerque EM. Sistema Nacional de Inovação no Brasil: uma análise introdutória a partir dos dados disponíveis sobre a ciência e tecnologia. Rev. de Economia Política 1996; 16(63):56-72.
35. Albuquerque E, Cassiolato JE. As especificidades do sistema de inovação do setor saúde: uma rese nha da literatura como introdução a uma discussão sobre o caso brasileiro. São Paulo: FeSBE; 2000. (Estudos FeSBE I). [acessado 2013 mar 19]. Disponível em: www.fesbe.org.br.

36. Albuquerque EM, Souza SGA, Baessa AR. Pesquisa e inovação em saúde: uma discussão a partir da literatura sobre economia da tecnologia. Cien Saude Colet 2004; 9(2):277-294.

37. Suzigan W, Albuquerque EM. A interação universidades e empresas em perspectiva histórica no Brasil. In: Suzigan W, Albuquerque EM, Cario SAF, organizadores. Em busca da inovação. Interação universidade-empresa no Brasil. Belo Horizonte: Autêntica Editora; 2011. p. 17. (Economia Política e Sociedade).

38. Palmeira Filho PL, Pieroni JP, Antunes A, Bomtempo JV. O desafio do financiamento à inovação farmacêutica no Brasil: a experiência do BNDES Profarma. Rev BNDES 2012; 37(junho):67-90.

39. Zago MA. Perfil da Produção Científica Brasileira. Mesa de discussão tecnológica. Inovações tecnoló gicas no Brasil. 2011. FAPESP: São Paulo; 2011.

40. Guimarães R, Souza LEPF, Santos LMP. Ciência Tecnologia e Pesquisa em Saúde no Brasil. In: Giovanella L, Escorel S, Lobato LVC, Noronha JC, Carvalho AI, organizadores. Políticas e Sistemas de Saúde no Brasil. Rio de Janeiro: Editora Fiocruz; 2012. p. 239-257.

41. Guimarães EA, Erber F, Araújo Júnior JT. A Política Científica e Tecnológica. Rio de Janeiro: Jorge Zahar Ed.; 1985. (Coleção Os anos de autoritarismo)

42. Pinho M. A visão das empresas sobre as relações entre universidade e empresa no Brasil: uma análise baseada nas categorias de intensidade tecnológica. Rev. Economia 2011; 37(N. Esp.):279-306.

43. Gadelha CAG. O complexo industrial da saúde e a necessidade de um enfoque dinâmico na economia da saúde. Cien Saude Colet 2003; 8(2):521-535.

Artigo apresentado em 12/03/2013

Aprovado em 20/04/2013

Versão final apresentada em 23/04/2013 